\title{
How SHOULd TeCHNOLOgY-Mediated ORganizational Change Be Explained? A COMPARISON OF THE CONTRIBUTIONS OF CRITICAL REALISM AND ACTIVITY THEORY ${ }^{1}$
}

\author{
David K. Allen \\ AIMTech Research Group, Leeds University Business School, Leeds University, \\ Leeds UNITED KINGDOM \{da2@lubs.leeds.ac.uk\} \\ Andrew Brown \\ Centre for Employment Relations Innovation and Change, Leeds University Business School, \\ Leeds University, Leeds UNITED KINGDOM \{andrew@lubs.leeds.ac.uk\} \\ Stan Karanasios and Alistair Norman \\ AIMTech Research Group, Leeds University Business School, Leeds University, \\ Leeds UNITED KINGDOM \{s.karanasios@lubs.leeds.ac.uk\} \{an@lubs.leeds.ac.uk\}
}

\begin{abstract}
In this paper, critical realism and activity theory are compared within the context of theorizing technologymediated organizational change. An activity theoretic analysis of the implementation of large-scale disruptive information systems in a public sector setting (in particular concerning paramedic treatment of heart attack patients and ambulance dispatch work activity) is used to illustrate how activity theory makes a significant contribution to critical realism, by (1) locating technology within "activity systems" and theorizing change through contradictions and congruencies within those systems; (2) developing recent critical realism-inspired theorization of the "inscription" of cultural and social relations within technology; and (3) developing recent insights of critical realist researchers regarding the way in which the performance management agenda is mediated through IS.
\end{abstract}

Keywords: Critical realism, activity theory, theory, information systems, organization change, evaluation

\section{Introduction}

It has been argued that information systems (IS) are much more than simply computer-based business systems but also concern the general evolution of human communication, implicating many diverse research fields and disciplines (such

\footnotetext{
${ }^{1}$ John Mingers, Alistair Mutch, and Leslie Willcocks served as the senior editors for this special issue and were responsible for accepting this paper.
}

as technology, economics, sociology, mathematics, linguistics, and engineering, among others) (Mingers 2001, 2006). In the context of such diversity, there have been important debates regarding the underlying philosophy and methodology for IS research. Best known are the debates between positivist and interpretive philosophical traditions, but in recent years dissatisfaction with the polarization of debate across these two extremes has encouraged the search for a "third way," beyond both positivism and interpretivism. Some have argued that the requisite third way can be found 
through adopting the ontology of critical realism, fostering explanation in terms of real structures, mechanisms, powers, and tendencies, rather than mere description or crude prediction. Others have argued that activity theory shows the requisite way forward, by locating IS within the context of activity systems (Allen et al. 2011). Neither exactly the same, nor entirely different, critical realism and activity theory have yet to be compared within IS studies (and seldom have been within any discipline; an exception is Wheelahan 2007).

This paper compares critical realism and activity theory, arguing that the two approaches can complement one another in forging a philosophically coherent yet practically attuned materialist framework for understanding IS and the way it supports and transforms work activity. The notion of an activity system is presented as a significant development by activity theory of nascent critical realist research into technology and culture. This presentation is developed and illustrated by the employment of activity theory to help explain organizational change through the implementation of large-scale disruptive IS in a public sector setting. Two cases of technology-mediated organizational change concerning paramedic patient treatment of heart attack patients and ambulance dispatch activity are analyzed, offering a detailed account of the processes of change through tensions and contradictions in activity systems and also introducing the concept of congruencies (temporary stabilization). Developing important critical realism-inspired insights concerning the inscription of social and cultural relations within technology, the analysis shows how the performance management agenda is mediated through IS implementation in such a way as to affect the power structure of organizations as well as organizational efficiency.

The paper is structured as follows: The next section will assess the contribution of critical realism to IS studies, in particular explaining technology-mediated organizational change. The subsequent section will argue that activity theory addresses some weaknesses of critical realism identified in the previous section, exposing some of the more exaggerated claims that have been made for the critical realism-inspired methodology of Archer (1995). Our research setting and method are then described. The following section illustrates, substantiates, and develops the contribution of activity theory through the example of its use in explaining two cases of technology-mediated organizational change concerning paramedic treatment of heart attack patients and ambulance dispatch work activity. We then further discuss the relationship between critical realism and activity theory, in light of the cases. Finally, we present our conclusion that critical realism and activity theory are largely complementary approaches essential to IS studies.

\section{Critical Realism, Information Systems and Organizational Change}

While organizational change has remained one of the most prevalent themes in the field of organization studies (Comfort 1994; Doolin 2003; Jones et al. 2005), in the context of IS it has centered on several interrelated concepts, including IS adoption (Davis 1989; Venkatesh et al. 2003), IS evaluation and success and failure (DeLone and McLean 2003; Petter et al. 2008) and IS implementation (Kim and Kankanhalli 2009; Sawyer and Southwick 2002). Like the broader IS field, the area of IS and organizational change has been dominated by positivistic and to a lesser extent interpretive positions. Despite its importance, relatively few scholars have approached IS research from the perspective of critical realism. A small core of IS authors explicitly mention the use of critical realism as a guiding philosophical perspective (Carlsson 2012; Dobson et al. 2007; Khoo and Robey 2007; Mingers 2006; Mutch 2010; Strong and Volkoff 2010), but it is more common that reference to critical realism is made, if at all, in an abstract way or en passant as the ontological and epistemological position most in line with the research (Lyytinen and Newman 2008; Rowley and Urquhart 2007). From within the aforementioned core, critical realism has been argued to help research in IS and organizational change in two key and related ways.

First, critical realism has been argued to help in the understanding of the specific conditions under which a given IS intervention can cause desired and unexpected changes in work activity (Carlsson 2012; Dobson et al. 2007), through an approach termed "realistic IT evaluation" (Oroviogoicoechea and Watson 2009). According to this approach, IS interventions do not "work"; rather, it is the actions of individuals that contribute to the IS working or not working and the related themes of IS success and failure. An IS initiative provides reasons and resources to enable (and constrain) different stakeholders and participants to make changes and it is in terms of the interplay of action and context that one can understand why an IS initiative succeeds, for whom, and in what context. Second, critical realism has been argued to help in the general theoretical understanding of IS as a mediator of organizational change (Volkoff et al. 2007). Here, critical realist contributions aim to overcome the extremes of technological determinism, on the one hand, where the physical structure of technology determines outcomes (inclusive of, for example, organizational outcomes), and what might be termed socio-cultural determinism, on the other hand, where technology has little or no extra-discursive effects, being entirely socially constructed, lacking any material properties that significantly constrain and enable such construction. As its name implies, critical realism is distinctive in attempting to 
overcome these extremes by retaining a strong realist stance, the tenets of which are explained below.

\section{Tenets of Critical Realism}

Critical realism, as first systematized by Bhaskar (1975, 1979), and clarified and developed by others such as Sayer (1992), Fleetwood (2005), and Elder-Vass (2010), offers a view of reality that is termed emergent powers materialism. According to this view, things possess causal powers by virtue of their intrinsic structures. For example, water boils at $100^{\circ} \mathrm{C}$ by virtue of its intrinsic structure of $\mathrm{H}_{2} \mathrm{O}$. The powers of things are emergent in the sense that, to continue the example, the power of water to quench a thirst is not a property of either of its constituents in isolation, hydrogen or oxygen, but emerges only as a property of the water molecule, $\mathrm{H}_{2} \mathrm{O}$, as an irreducible whole. The critical realist view of emergent powers is developed for the social realm through a notion of social structure as follows.

Within critical realism, the concept of social structure refers to enduring social relations of social positions into which individuals are said to "slot." These include, for example, the relationship between (the position) landlord and (the position) tenant or between employer and employee or between doctor and patient. In each case, occupancy of a social position by an individual confers upon them specific constraints and enablements (e.g., in the case of a tenant, being constrained to pay rent and enabled to use the accommodation). According to critical realism, social structures constrain and enable the very activities through which they are reproduced or transformed. In this respect they are unlike natural structures, which generally can exist irrespective of human activity. Nevertheless, social structures are held by critical realists to be analytically separable from agential activities and in this sense analogous to natural structures. The key insight here is that one cannot read off the activities of individuals or groups from abstract social structures such as the structure of the capitalist economy; social activity is, as it is sometimes phrased, relatively autonomous from its social structural context.

As we shall see below, unlike the theory of social structure, the theory of culture has until recently been rather neglected within critical realism (an exception is Archer 1996), and so there is no generally accepted tenet of critical realism in regard to culture. However, Archer $(1995,1996)$ does propose an influential methodology for the understanding of both social and cultural change termed the morphogenetic approach that is explicitly grounded in critical realist philosophy. The approach has three stages.
- Stage one: The researcher identifies relevant antecedent social structural and cultural relations.

- Stage two: The researcher examines the activities of agents that are constrained and facilitated by the identified antecedent social structural and cultural relations.

- Stage three: The researcher examines the effect of the agential activities on the antecedent social structural and cultural relations. This effect may be to reproduce social structure and cultural system unaltered (morphostasis) or to modify or transform them (morphogensis).

Extant critical realism-inspired contributions to explaining technology-mediated organizational change are embedded within and augment Archer's methodology, as we shall see below.

\section{Technology-Mediated Organizational Change and Inscription}

Within IS studies, critical realism has been argued to help in rectifying a widespread neglect of the specific properties of technology noted by Orlikowski (2010) while avoiding the tendency of Orlikowski's own "entanglement perspective" to neglect wider structural factors (Mutch 2010; Strong and Volkoff 2010; Volkoff et al. 2007). A key concept is that of inscription. Social structure and culture are said to be inscribed within the material components of IS (hardware, software, etc.) in a way that may help sustain these structural and cultural relations through organizational change, thereby impacting upon that change (Mutch 2010). For example, Mutch (2010) shows how the wider social structural or cultural imperative of performance management may be inscribed within a data storage system through such a system being designed to concentrate information in the hands of management, affecting the power relations within the relevant organization. Critical realist contributors locate IS, and the social and cultural relations inscribed therein, at the first stage of Archer's three stage schema, to be analyzed prior to the activities of agents (stage two) and socio-cultural elaboration (reproduction or change in stage three).

The development of a critical realism-inspired concept of inscription helps to bring wider social structures and culture to bear in the analysis of technology-mediated organizational change. However, critical realism has, in general, only very recently begun to address crucial issues pertaining to culture, technology, and semiotics (signs and meaning) (Fairclough et al. 2004; Mingers 2006; Mutch 2010; Nelhaus 2007; Volkoff et al. 2007). In particular, the notion of inscription could be 
described, to some extent, as an assertion unless the notion is supplemented with a description of the specific mechanisms or processes whereby technology conveys meaning to agents, the particular way in which subject and object emerge and interact in this case, and so the particular way in which social or cultural relations are in fact inscribed. Elder-Vass (2010) has stressed the imperative of explicating the mechanisms whereby causal powers emerge, explicitly singling out semiotics as an area where this imperative is sometimes not met. Nascent attempts in this direction by Elder-Vass and other critical realists interested in culture and technology suggest two problems with the idea of inscription of social and cultural relations in technology.

\section{Problem 1: Nonmaterial Technological Objects?}

Faulkner and Runde (2011) bring out an apparent contradiction with materialism to which the informational aspect of technology leads: the existence of what they term (provocatively for a materialist) nonmaterial technological objects. These are objects, such as computer codes or, more generally, the meanings of signs and symbols, inclusive of language, that have no necessary relation to their particular material bearer. Thus the very same computer code can be borne by entirely different material entities such as a set of electronic impulses or by handwritten binary digits, thereby having no intrinsic relation to any particular material manifestation. Two difficult questions for materialism arise from Faulkner and Runde's analysis. First, where is the material structure by virtue of which the power of signs and symbols to convey meaning is possessed? Second, if there are important nonmaterial technological objects, does this contradict the argument by some critical realists in IS that it is the material properties of technology that must be exclusively focused upon?

\section{Problem 2: Analytical Dualism?}

Mingers's work tries to fill the gaps in critical realism regarding the relation of subject and object by drawing on work that is not inspired by critical realism (e.g., systems theory and semiotics.) Mingers stresses that ongoing activity is inseparable from the production of meaning and knowledge, in short, "acting is knowing, and knowing is acting" (Mingers 2006, p.52). But this view would appear to problematize the three stage schema of Archer's morphogenetic approach whereby cultural meaning is to be analyzed prior to and separate from agential activity. A similar contradiction with Archer's approach is explicitly brought out in recent debate between Archer and Elder-Vass (2012) (although a clear indication of the undeveloped nature of critical realism with regard to culture and technology is that Archer and Elder-Vass do not cite Mingers). Elder-Vass argues that "norm circles" involving the activities of concrete agents, not abstract relations of social positions, are inseparable from cultural systems. Yet his view is interpreted by Archer as a rejection of the central idea of her morphogenetic approach to culture, the idea that one can start with an analysis of culture (and by extension technology) that abstracts from agential activity (stage one) prior to considering agential activity (stage two). This central idea is termed by Archer "analytical dualism." Clearly, then, there is much room for development of critical realism-inspired approaches to technology and culture. Let us see below how activity theory can help.

\section{The Contribution of Activity Theory}

Over the last two decades, interest in activity theory as a methodological and conceptual tool to understand systems design (Kuutti 1999; O’Leary 2010) and information science (Allen et al. 2011; Spasser 1999; Wilson 2008) has grown. Recently, there has also been a growing interest in the use of activity theory within the field of IS, with work focusing on mobile IS change and the public sector (Allen and Wilson 2004; Karanasios et al. 2009; Pica et al. 2004; Sørensen and Pica 2005; Wiredu 2007; Wiredu and Sørensen 2006). Several approaches to the use of activity theory in IS exist: Kaptelinin et al.'s (1999) activity checklist has been utilized for human-computer interaction design and evaluation (Fuentes et al. 2004); Quek and Shah's (2004) activity theoretical evaluation method attempts to develop the abstract concepts of activity theory as a practical tool for IS practitioners engaged in evaluation. Guy's (2005) use of patterns with activity theory has also been used to support evaluation; and, Engeström's (1987) third generation activity theory and its related concepts provides a clear framework for coproduction of work systems.

\section{Activity Theory in Relation to Critical Realism}

In relation to critical realism, two aspects of the roots of activity theory are particularly noteworthy. First, critical realism is, like activity theory, situated in a tradition which embraces Marxian themes regarding a dialectically changing material and social reality, themes that go beyond positivism and interpretivism. The Russian philosopher Ilyenkov did most to develop these philosophical underpinnings of activity theory (Bakhurst 1991; Ilyenkov 1977) and his work has been compared to critical realism (Brown 2002). Second, activity 


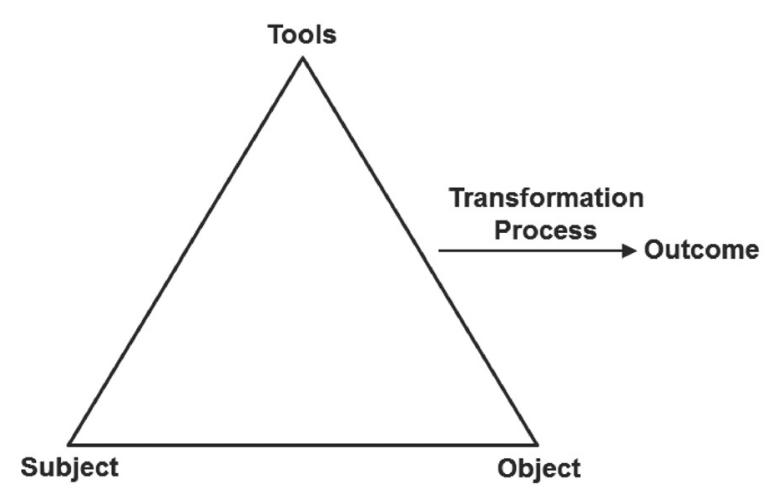

Figure 1. Basic Activity Systems (adapted from Vygotsky 1978, p. 40)

theory foregrounds as essential those very aspects that have been rather neglected until very recently within critical realism (i.e., semiotics and the mediation of subject and object by technology, as discussed above). The central idea as set out by Vygotsky (1978) is that artefacts have a mediating role in activity, represented in a basic model of human activity which is usually illustrated in the form of a diagram (see Figure 1).

As illustrated in Figure 1, an activity is undertaken by a subject (a person or collective), with an underlying motivation to act on an object (typically a person, collective, or thing) in order to achieve an outcome. Objects have a life of their own, which is emphasized when objects resist the attempts of the subject to control them. This is particularly true when it is other people that are the object of an activity (Engeström 2000). The placeholder "tool" in this triangular model is emphasized within activity theory. It does refer, as is commonplace, to useful material artefacts such as a hammer, recognizing the material and social aspects of such items, their form and function (in line with Faulkner and Runde's (2009) critical realist analysis). However, the term tool in activity theory also includes a different type of mediator, namely meaningful items such as signs, symbols, language, etc. referred to by Ilyenkov (1977) as "ideal forms." As noted above, such meaningful items are deemed to represent nonmaterial objects by Faulkner and Runde (2011). Ilyenkov's activity theoretic analysis of ideal forms offers a sophisticated materialist resolution of the difficulties for materialism that Faulkner and Runde raise.

Ilyenkov (1977) argues that ideal forms function to represent other objects by virtue not of their own material properties, but of the material properties of the activity system of which they are part-by virtue, and as part, of the engagement of subject and object in material practice. Once viewed in the context of the overall activity system, ideal forms do not escape materiality and do not represent nonmaterial objects; ideal forms are material objects that function to represent other material objects within, and by virtue of, an objectoriented activity system. Thus, to take Faulkner and Runde's (2011) example of computer codes, it can be seen that computer codes intrinsically relate to material activity once they are brought down to earth by being viewed as an essential and characteristic part of a specific activity system (the location of the computer within a wider activity system is part and parcel of the activity theoretic approach to human-computer interaction). According to Ilyenkov, it is only when illicitly abstracted from the specific activity systems of which they are an essential and characteristic part that the referents of ideal forms can be wrongly construed as nonmaterial. In overcoming the contradiction between ideal forms (involving an apparent abstraction from material properties) and emergentist materialism (disallowing any such abstraction) through the concept of a system of object-oriented activity, Ilyenkov offers the deepest of foundations for the analysis of activity systems.

Drawing on Ilyenkov, Engeström $(1987,1993)$ has extended the original model of Vygotsky (later augmented by Leont'ev 1978), incorporating all aspects that Ilyenkov argues to be inseparable from object-oriented activity systems, as set out in Figure 2.

Figure 2 shows Engeström's expansion of the core elements of an activity system, bringing attention to the larger social context by adding rules and norms, the division of labor, and the community as interrelated elements that influence an activity. By doing so, he makes explicit various aspects of what critical realists refer to as social structures and culture, along- 


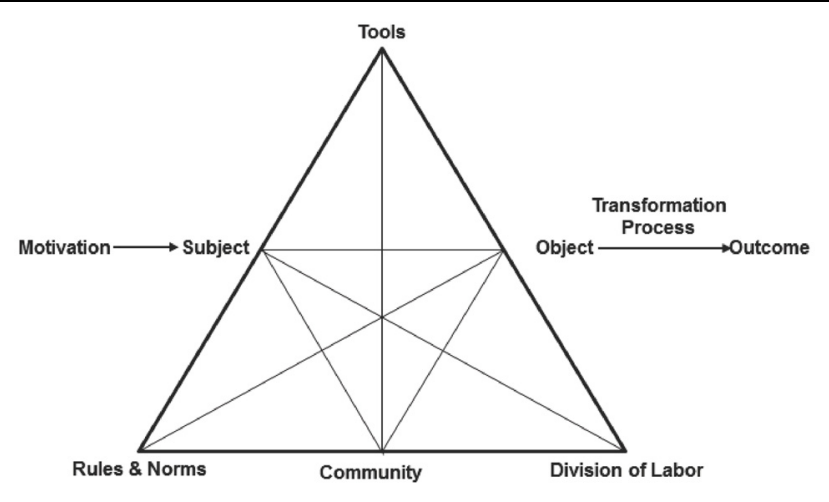

Figure 2. Engeström's Activity Model (adapted from Engeström 1987, p. 78)

side agential activities. However, where critical realism tends to see structure, culture, and agential activities as consisting of analytically separable mechanisms in interaction or interplay, for activity theory, the various aspects are analytically inseparable moments of a single unit of analysis, the activity system.

Recall that Archer (1996) argues that the analytical separation of cultural system and agential activity is essential in order to examine the interplay of culture and agency that causes change over time. Yet, for activity theory, system and activity are analytically inseparable and form a single unit of analysis: the activity system. Because activity theory insists on the very point that Archer refuses - the analytical inseparability of system and activity - adoption of Archer's position would logically entail leveling at activity theory the same accusation as Archer does in fact level at Elder-Vass's approach (Archer and Elder-Vass 2012); to wit, the accusation that activity theory cannot adequately theorize change because it does not analytically separate cultural system from agential agency. In the cases that follow, we will employ activity theory to theorize technology-mediated organizational change. Our purpose is not to criticize Archer's morphogenetic approach; rather, our purpose is to question the argument that the morphogenetic approach, and in particular the analytical dualism upon which that approach rests, is the only valid method for understanding organizational change. Indeed, and to anticipate, we will find that, despite their differences, respective applications of the two approaches (the morphogenetic approach and activity theory) in IS can and do come to similar conclusions, in particular regarding the inscription of performance management imperatives within IS technology. That two different abstract methods can lead to similar concrete results highlights, it will be argued, the complex relation between the abstract and the concrete.

\section{Contradiction and Change}

How, then, according to activity theory, should change be theorized? For activity theory, the motor of change is contradiction. Contradictions refer to anything within the system that opposes the overall motive of the system, the aim or purpose that subjects within the system are individually or collectively striving toward. Contradictions threaten the very existence of the system, since an object-orientated activity system is defined in terms of its motive, yet they are likely to be pervasive, and they lead to change or development of the system. If we initially define a contradiction straightforwardly "as a tension, contrast, denial, or opposition between two propositions" (Murphy and Rodriguez-Manzanares 2008a, p. 1063), then the thrust of activity theory is to locate such propositions within the context of an activity system whereby contradictions will refer to

a misfit within elements, between them, between different activities, or between different developmental phases of a single activity....[and so] manifest themselves as problems, ruptures, breakdowns, and clashes (Kuutti 1999, p. 34).

Primary contradictions are those found within a component of the activity (i.e., in the rules, norms, object, etc.) and secondary contradictions are those that occur between constituents of the activity (for instance, between the community and the tool) (Engeström 1987).

For activity theory, contradictions are a cultural-historical force that destabilize activities, leading to constantly evolving and transforming activities, in which "equilibrium is an exception and tensions, disturbances and local innovations are the rule and the engine of change" (Cole and Engeström 1993, 
p. 8). Contradictions shape an activity (Engeström 2001; Wiredu and Sørensen 2006) and as they arise, or are observed, they expose the dynamics, inefficiencies, and, importantly, opportunities for change (Helle 2000). Internal contradictions within an activity system precipitate its development and reveal opportunities for creative innovations and for new ways of enacting the activity (Foot 2001). Engeström (2001) suggested that, as contradictions are aggravated within an activity, some individuals may begin to deviate from the activity's established norms, which in some cases may lead to a deliberate collective effort to change the system (issues, highlighted by activity theory, which are not customarily dealt with by the IS community).

While undoubtedly useful as an analytical lens and guiding empirical principle, the notion of contradictions can be problematized. Wiredu (2007) noted that the activity community may have contradictory motives driving the community's collective activity. The idea of contradictory or multiple motives may seem to threaten the whole concept of an activity system, which is defined in terms of its motive. However, recognition of multiple motives does no more than reflect the complexity of reality so as to highlight the importance of the issue of abstraction (e.g., from one or more motives), and the need to develop from abstract to concrete. A second problem is that contradictions are not always acknowledged or resolved (Murphy and Rodriguez-Manzanares 2008b; Nelson 2002), meaning that transformation does not occur. Parallels have been drawn here between the (for example, ecological) unsustainability of human activity and the lack of change of that activity (Blunden 2010). A related problem is that contradictions may not be obvious, openly discussed, or, as Capper and Williams (2004) noted, visible or discussable. In this case, they may be culturally or politically difficult to confront (Capper and Williams 2004).

\section{Congruency and Stability}

Mingers (2011) established philosophical connections between systems thinking (von Bertalanffy 1971) and critical realism and noted that the notion of feedback or circular causal relations is absent from Bhaskar's work. The notion of feedback entails that forces within and external to a system lead to balance or change, in intended or unintended ways (for discussion on the self-regulated nature of biological and mechanical systems, see Shannon and Weaver. 1949; Wiener 1948). Clearly, contradiction plays a similar role in fostering change within activity theory as feedback does in systems theory (Levins 1998). However, this analogy raises the question of whether there is an analogue in activity theory for the kind of feedback that leads to balance rather than fostering change. Although in our view overplaying analytical dualism, a welcome aspect of Archer's approach is the incorporation of morphostasis (internal forces for balance), as well as morphogenesis (internal forces for change), drawing from systems theory (Buckley 1967). While activity theory rightly stresses contradictions leading to change (morphogenesis, in Archer's terms), we suggest that it is also important in concrete research to recognize what we call congruencies, which foster reproduction rather than change (morphostasis in Archer's terms).

The cases below will illustrate, substantiate, and develop the arguments presented above. In particular, they will show how one can incorporate and develop key insights of critical realist scholars in IS studies, such as that of the inscription of social and cultural relations, without incorporating analytical dualism, in order to help explain technologically mediated organizational change through contradictions in activity systems. The cases will also illustrate and develop the notion of congruencies as stabilizing forces within activity systems.

\section{Research Setting and Method}

\section{Research Setting}

The empirical data that forms the base of this paper centers on the UK Ambulance and Patient Transport Service, hereafter the Trust. The research was conducted in collaboration with the Trust, which serves an area of approximately 1,500 square miles and manages some 60,000 calls a year. There are a total of 35 ambulances of which approximately 25 are available at any given time. The Trust also has 12 "first responder" vehicles that arrive on the scene faster than traditional ambulances, but with only one paramedic and less equipment. Vehicles and crews are distributed across ambulance stations within the geographical area served. The Trust operates a central call handling facility which handles emergency calls (999), general practitioner (GP), patient transfer services (PTS), and contact with midwifery services.

\section{The Cases}

The remit of our research was as an independent investigation of two related IS implementations in the Trust, examining what aspects of the implementation, in each case, were working well, what areas needed modification, and how the modifications led to changes and improvement in the work 
activity. The use of activity theory provided a structure for framing questions concerning the work activity and understanding change, such as (1) what changes did the IS intervention engender; (2) what were the important imperatives; and (3) what aspects (social, cultural, and others) enabled/ disabled these changes. These questions mirror the frames of inquiry adopted in critical realist evaluation (Carlsson 2012). Crucially, in both cases we worked directly with the Trust and the government-sponsored public safety network, on which the dispatch and navigation systems ran, to ensure the Trust received the maximum benefit from the implementation and that the successes of this venture could be transferred to similar implementation projects with other Trusts. In line with critical realism the goal was to develop understanding that can be used by practitioners and stakeholders to improve the implementation of IS (Carlsson 2012) and the process of technology-mediated organizational change.

The first case focuses on the Trust's practice of transmitting ECG reads to a hospital coronary care unit (CCU) using a mobile health information system, allowing paramedics to treat heart-attack patients immediately with thrombolizing drugs. In the analysis of case one, we focus specifically on the fundamental role of contradictions as sources of change and development after implementation of the mobile health system. Through this lens, we reveal some of the unintended consequences of the IS intervention on the work activity rules and norms and the division of labor and explain how it aggravated tensions between the community and the subject. We also demonstrate how these contradictions led to development and change in the activity system. We establish that the contradictions act as a form of feedback leading to congruency in the activity and acceptance of the mobile health system.

The success of this case led to a broader implementation of the information system in the Trust, leveraging the technology of the first case. This follows the activity theory perspective, which posits that an activity is part of a wider network of activity systems (Engeström 2001), which can become connected or potentially fuse, in part or wholly, through their exchanges (Engeström 1987).

The second case focuses on an incident control system (ICS), the features of which included instant text transmission to ambulances, a remote tracking network of each ambulance's location, and satellite navigation for faster arrival on the scene. In case two, we take a different approach to case one and highlight the contradictions that led to the emergence of the ICS solution. Using this broader cultural-historical lens we examine the implementation and position the successful implementation of the ICS solution and the observed congruencies in the context of transformation of the previous system. Our use of activity theory illuminates key issues highlighted in our prior discussion related to inscription of social and cultural relations without recourse, we will argue, to analytical dualism.

\section{Data Collection and Analysis}

To frame our study we were guided by the underlying principles of activity theory, namely (1) the object-oriented activity system is taken as the prime unit of analysis, seen in relation to a network of other activity systems; (2) an activity has multiple voices, which appear through interactions between the community and subject; (3) activity systems are historical activities that typically form over long periods of time; (4) the fundamental role of contradictions as sources of change and development; and (5) the possibility of transformation and the reconceptualization of the object and motive (Engeström 2001). Although going beyond critical realism in the theorization of technology-mediated organizational change in the manner suggested earlier, these principles are similar to critical realism in being relatively open with respect to particular methods, providing an overarching frame and conceptual tools for inquiry: they provide heuristic guidance rather than strict rules. The crucial distinguishing feature of the activity theoretic overarching frame, significant at even this first stage of the research process, was the ongoing attention to identifying and exploring contradictions within an overall activity system.

The research was carried out with ambulance crews, managers, and control room staff as well as technical staff in the Trust across approximately 50 semi-structured interviews (lasting from 30 minutes to 2 hours). An interview-based approach, guided by activity theory, was selected across the two cases because it was felt that this would be the best way of obtaining a detailed understanding of factors leading to and surrounding the organizational change and success of the IS implementation. We also observed practice, which involved accompanying paramedic crews during their work activities. Details of the observations were captured in field notes taken in situ. Over 100 hours of field observation were conducted. A reason for using ethnographic fieldwork was to observe and study the activity as a complex social, cultural, and political system (Harvey and Myers 2002), in particular as an objectoriented activity system as per activity theory.

The collection of data was a collaborative process, which resulted in added richness provided by the complementary 
insights of the research team (Eisenhardt 1995). The collected material was then developed into the case material presented. Interviews were digitally recorded and then transcribed. Where clarification or verification on themes was sought, subjects were contacted by e-mail or telephone. Atlas Ti was used for the categorization of initial concepts arising from interviews and other data, in turn guiding and directing the theoretical sampling process. As sampling progressed, concepts were constantly compared leading to the generalization and consolidation of categories (axial coding). The intent was to produce a thick narrative, a complete description of the complex interactional process-orientated situations found within the case, a narrative crucially informed by our activity theoretic perspective. For example, it was the identification of the relevant activity system and of contradictions and changes within it that was to determine the stages of the research process and the explanatory theory- not the three stage schema of Archer's morphogenetic approach.

\section{Results}

\section{Case One: Mobile Health System}

The first case examined the introduction of a mobile health system to the work activity of treating patients. The system involved a 12-lead electrocardiogram (ECG), where electrodes are attached to a patient's body and recorded by a device external to the body feeding data wirelessly (the patient's vital signs) directly from ambulances to hospital coronary care units (CCUs), where the decision to authorize the delivery of clot-busting drugs is made remotely. This enabled drug delivery to occur minutes after the ambulance arrived at the scene, rather than minutes after the patient arrived at the CCU. The effects of this drug are dramatic in appropriate cases and can be a material factor in extending life expectancy and in reducing the amount of time spent in hospital in recovery from myocardial infarctions (MCIs). The measure used by Trust staff is that of pain to needle time (the difference in time between onset of pain and the drug intervention). A reduction of one minute between pain to needle equates, anecdotally and at an approximate level, to an additional week of life expectancy. Early treatment reduces both the time a patient needs to spend in hospital and the overall period of recovery after an MCI. However, and critically, the drug carried a risk, estimated at about 1 percent, of causing a fatality, and a drug carrying that level of risk had not previously been available to the ambulance crew or paramedic. The system was available on all high dependency and emergency ambulances and operated over a dedicated dataenabled radio. At the time of investigation, the system had been in use for approximately 18 months.

\section{Context and Conditions Surrounding the IS Intervention}

There were several key motivations that led to the introduction of the mobile health system. The major motivation concerned the measured health benefits of providing the clot busting drug to patients more rapidly. The attitude taken to the implementation was that a change was needed, and this was the most effective, and indeed the only sensible, path offering the ability to handle data on a secure and resilient system designed specifically for the public safety community.

Figure 3 illustrates the work activity system post-implementation of the mobile health system. The figure shows that an ambulance crew or paramedic (the subject) acted upon the patient (the object) in order to satisfy the motivation of treating the patient. This interaction is mediated by physical tools, such as those comprising the mobile health system, as well as mental tools such as expertise, training, and language. The activity involved a broader community, which included onlookers and the $\mathrm{CCU}$, and a division of labor; in this case, we center on the task of administering the clot-busting drugs. The inclusion of the subject, object, and community within one unit of analysis encapsulates the multiple voices that frame an activity. The activity was also governed by rules and norms. In this case, it is important to consider that the system was implemented within a political environment where changes in the management and governance culture within the National Health Service (NHS) had resulted in a far greater emphasis on data for the purposes of clinical audit and the continuous improvement of patient care. The ability to route such data using the mobile health system provided a high-level of control over, and access to, this data. While the introduction of a mobile health system can create the potential for transgression of existing rules and an opportunity to subvert or avoid official means of communication and record keeping (Manning 1996), here it provided a constant reinforcement of proper process because of the level of detail recorded by the system. There is a duality of the sort described by Brooks et al. (2008) where the constant interaction of the professional with the system maintains and develops the control and direction of their actions.

Therefore, within the context of the broader culturalhistorical environment, the technology had both a clinical treatment and clinical auditing function inscribed within it. While this concept was not explicitly articulated, it emerged during our data collection with the senior managers as one factor that contributed to the choice of system and ultimately influenced the rules and norms that governed the activity.

The broken lines in Figure 3 represent the secondary contradictions identified within the work activity (of paramedics 


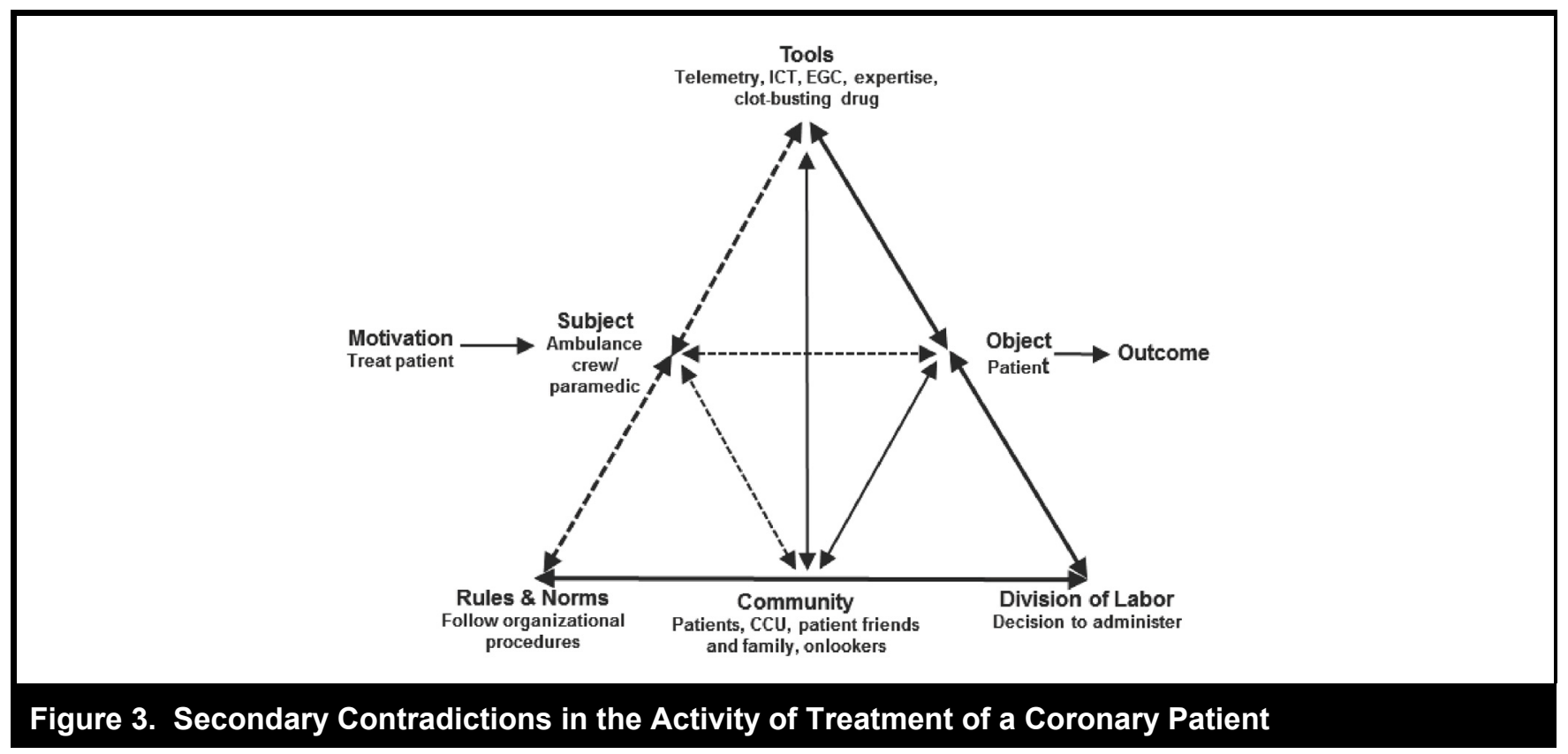

treating patients). We focus our analysis on the primary (which occur within constituents) and secondary (which occur between constituents of the activity) contradictions in order to reveal some of the critical unintended consequences of the intervention on the activity and how it aggravated tensions between the activity constituents. We argue that these contradictions act as a source of tension and change (as a form of feedback) leading, in this case, to a more advanced form of the activity through greater congruencies in the work activity.

\section{Decision Making and the Division of Labor}

After the mobile health system was implemented, we noted a major contradiction between the subject of the system (the paramedics/ambulance crew) and the division of labor relating to the delivery of the drug. Prior to implementation, the crews had only one choice: to provide treatment and focus on taking the patient to the CCU (without delivering the drug). After implementation, they were given the alternative of providing initial treatment and driving to the CCU or using the system to relay information to the staff in CCU who would advise on treatment and whether or not to deliver the drug in situ. The action of connecting the patient to the system and relaying information to the CCU passed decisionmaking responsibility to the CCU. In the cultural-historical context of the NHS, the use of the mobile health system, which moved responsibility of decision making from the paramedic to the CCU, could be seen as the safe option for the paramedic. Paramedics could use the technology defen- sively, absolving themselves of responsibility. Paramedics identified situations (close to a hospital where there was a short transfer time, for example) where the correct judgement would be to travel to the hospital rather than spending time getting the system set up; however, they made the decision to use the system as this passed decision making responsibility to the CCU. Effectively, this contradiction manifested in both changes to the division of labor and, in part as a result of this, in changes to the rules and norms which controlled decision making and behavior within the system. So, with regard to the division of labor, there was now a new player (the CCU) in the activity system, as noted above. One paramedic commented that this could make crews look at "how to use it [ECG] rather than whether to use it." Along these lines, another paramedic stated:

People abdicate any sort of responsibility when they have telemetry in order to pass that responsibility onto a doctor, hospital, or somebody who they think knows better than they, which can lead to problems.

When probing further, this was seen to be linked to the creation of a contradiction between the tools that was caused by the introduction of the mobile health system. That is, between the expertise and knowledge of the paramedic (mental tool) and the capability offered by the technology (physical tool). This led to a shift in rules and norms concerning the activity, the normal work practices and, importantly, the pressure and responsibility of the paramedics. The norm was becoming the use of the system, rather than treating it as a tool to be 
deployed when appropriate. One paramedic commented that this could have a significant detrimental effect if staff were to take unnecessary time by using the system in a defensive manner in cases where it is unlikely to provide benefit (for instance, not all chest pain is an MCI). The Project Manager recognized this tension and commented:

We are asking crews to give something that they have never historically given before. All the drugs we use make people better. We are now giving a drug that has a 1 in 100 chance of killing somebody....and they've got to make that decision.

\section{Reconceptualizing the Paramedic-Patient Relationship}

If the decision was made to routinely use the system it also led to a contradiction concerning the object of the activity system, from treating the patient (the object) to a more mechanical following of instructions. Paramedics commented that the use of the system would take attention away from the patient and "interfere with doing the job," in regard to paramedic-patient interaction. That is, the crew were paying attention to the tools that mediated the activity and the subsequent instructions from the hospital, rather than directly to the patient.

Arguments for medical automation are centered on cost reduction, the management of errors, or, as in this case, improved patient outcomes via evidence-based medicine (Sintchenko and Coiera 2003). Here, however, some crews argued that the technology led to a loss of power and precipitated a shift in emphasis from real activities (interaction with patients) to prescribed tasks (managing the system), as the technology made their know-how irrelevant.

We also noted similar contradictions experienced between the paramedics and the community, from both perspectives. The use of the mobile health system introduced social-spatial changes. The ambulance may be stationary for up to 10 minutes after picking up the patient (while the wireless connections are made to the hospital and treatment commences in the ambulance), without an explanation being given to the patient's family members or concerned onlookers. This often aggravated tensions between the patient's friends and family as it was interpreted as the ambulance service "wasting time." As one paramedic put it,

Relatives and carers, people in care homes, etc., are very concerned when they see an ambulance arrive, sirens, lights, the full panoply of an emergency, the patient is rushed out to the ambulance, a huge sense of urgency and then the vehicle sits there.... this has on a number of occasions caused calls to control: "what is going on, we have called an ambulance and nothing is happening, they are just sitting here, have they broken down?"

The activity system, as formerly conceptualized and delivered to the community, involved an ambulance arriving and, in accordance with known practice and received wisdom (much of which comes from television dramas, for those not familiar with hospitals and paramedics), the expectation is one of urgent action and movement. In this newly developed activity system where the ECG read was relayed to the hospital and, thus, required the ambulance to stay still during the delicate task of attaching the ECG (the process of connecting the ECG to the patient in order to relay vital signs to the $\mathrm{CCU}$ ), a tension was immediately raised between the actions of the subject (paramedics) and the community (concerned relatives, carers, or others). This, in fact, as noted below, provided the basis for a learning cycle through which paramedics learned that one of them needed to take perhaps 20 to 30 seconds to explain how the process now worked to onlookers concerned about the patient. This is an example of how a contradiction can act as feedback, leading to changes in rules and norms within the activity and a more congruent activity. In this case, the paramedic would adapt to this contradiction by adapting scripts and routines when dealing with the community to mitigate the impact of the technology and allay concerns. A script revolves around predictive rules derived from a stereotyped event sequence: they base their actions and their assumption of others' actions on previous occurrences of a situation. As the project manager noted,

They are beginning to develop their own script so far as patient management is concerned, which is good to see and crews who work regularly together have got a very good routine going, which is something they haven't been taught, they've developed that themselves.

\section{Case Two: Incident Control System}

The second case also focuses on the activity of paramedic crews treating patients at the scene. Within this activity, we specifically focus on the actions surrounding transportation, routing and dispatch of ambulance vehicles and crews. To enhance this activity an incident control system (ICS), which consisted of vehicle-mounted computers operating over the TETRA network, was introduced, allowing for change surrounding: 
(1) Dispatch of ambulances to incidents by data message rather than voice. Typically the information for a dispatch by either method includes the following information (where known): name of patient, address, possible symptoms, person making report, and any significant information held on file.

(2) Sending detailed updates to ambulances en route to scene.

(3) Recording of accurate dispatch, arrival, and clear times for the patient record form (PRF).

(4) Satellite navigation (SatNav) plotting together with automatic vehicle location systems (AVLS) to allow vehicles to be routed to incidents with less need for local geographical knowledge on the part of drivers.

In this case, we focus specifically on key primary and secondary contradictions that arose from the implementation of the ICS. These contradictions, we argue, were so severe that they could have led to ultimate failure of the ICS intervention. However, by understanding the contradictions that existed in the work activity ex ante implementation of the ICS, which we argue acted as a source of change (and a form of feedback, which manifested in the form of the ICS), the imperfect ICS solution presents several major congruencies that led to its acceptance and success. To do this, we first provide an account of the use of tools within the activity prior to the introduction of the ICS.

\section{Context and Conditions Surrounding the IS Intervention}

In our investigation we noted a number of motivations for the implementation of the ICS, based on a synthesis of contradictions within the previous work activity and between advances in available technology compared to the system that was in use. The latter can be viewed as outcomes of unrelated activities, following the notion of activity theory that tools carry with them particular cultural-historical remains from their development. In this case, the motivations differ from the first case, which was based on the life saving properties of the mobile health system alongside the clot-busting drugs. In this case, the motivations are linked to several major contradictions that existed in the activity prior to the implementation of the ICS. The motivation for this system implementation was intimately linked to the resolution of these contradictions.

The first of the major contradictions within the previous work activity was that the tool for managing incidents (an analogue voice radio, AVR) was in urgent need of replacement as a result of both a lack of voice capacity and data capability and the availability of more capable alternatives, which offered data transmission and improved voice handling. This was a primary contradiction within the extant tool: quite simply, it was rapidly becoming obsolete. The second contradiction is related to the first contradiction and impacted upon the rules and norms of the activity; namely, that the system was increasingly unreliable, having suffered a number of minor failures and one especially severe failure in the 18 months leading up to replacement, at a time when government policy stressed the importance of communications. This major failure required significant repair, with hard-to-find parts, meaning the system was off-line for a considerable length of time. While this did not impact on the ability of the Trust to meet the demands placed on it, it did push the issue of a replacement system to the fore.

Congruencies within multiple internal and external motivations also influenced both the decision to implement the systems and the nature of the technology implemented. The technology supplier offered terms that were seen by the Trust as being particularly attractive because the implementation was congruent with the supplier's strategic motive of using implementation as part of a long-term market penetration strategy. They wished to create an exemplar, which could demonstrate the capability of the system to other potential customers. Senior managers felt that a shift to a new, datacapable radio system was a clear fit with overall direction as set out in articulated NHS plans for ambulance services with regard to communications. Equally, paramedic staff were aware that the implementation of the system would support their norm of providing professional patient care by enabling them to provide a more rapid response to patient need.

This system, like the mobile health system described in the first case, was viewed as a successful implementation. The ICS was found to improve the mean time of despatch, both in terms of the crews receiving information and reacting to the incident. The SatNav system allowed more effective routing to occur and thus reduced both actual and average estimated time of arrival. On arrival, crews had more and better quality information via the ICS. The new system was seen as a creating a better working environment than previously. As one paramedic noted, "you had to write the door entry code on the back of your hand while the vehicle goes round a corner and over a bump (making the code illegible)," which delayed entrance to a building to treat a patient.

Figure 4 illustrates the work activity of responding to treat a patient post-implementation of the ICS. Similar to the first case, it highlights the activity of treating a patient; however, here we focus specifically on the action of responding to the call. The broken lines in Figure 4 represent secondary contra- 


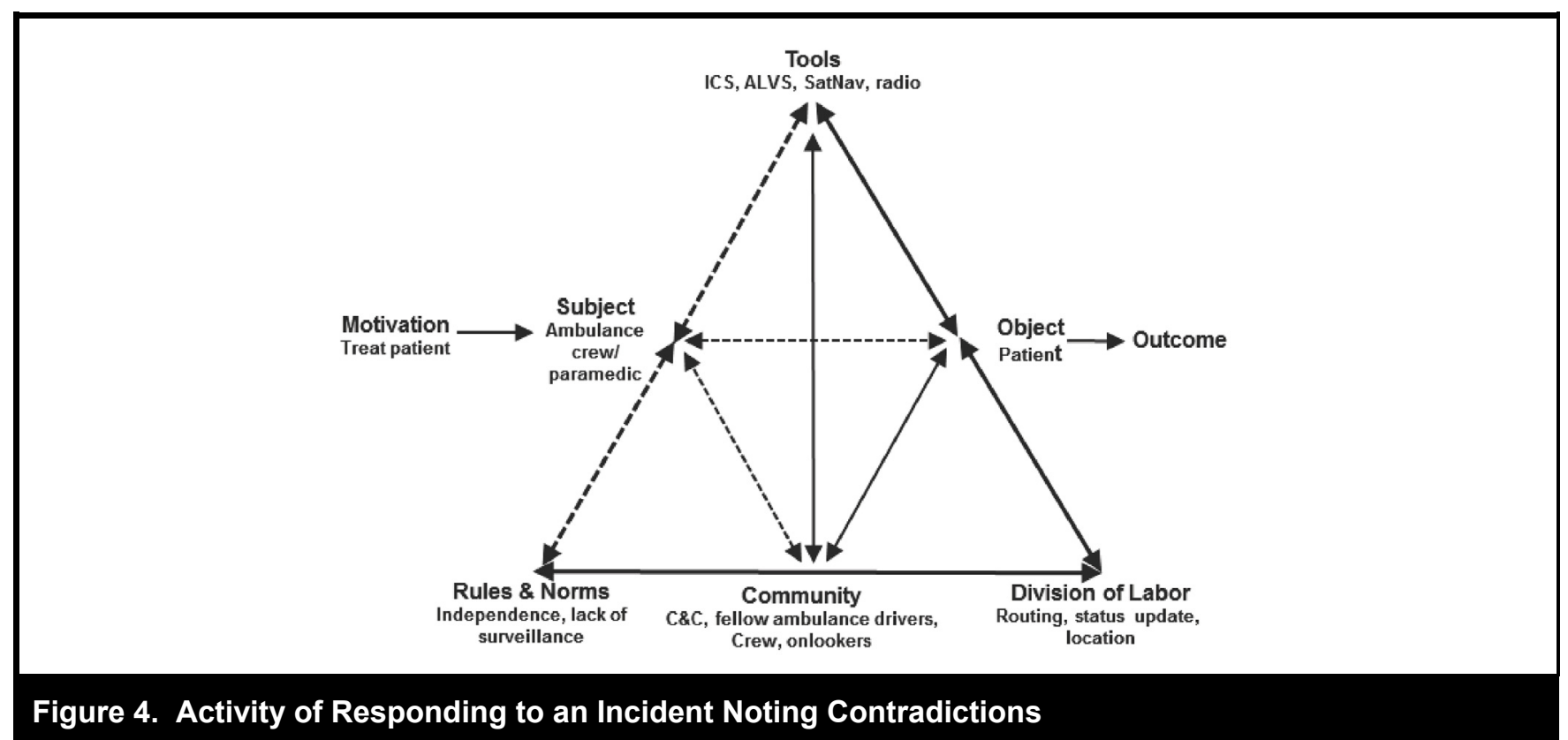

dictions. In the following paragraphs, in light of the preimplementation contradictions (discussed above), we outline the post-implementation contradictions, both primary and secondary, in order to reveal the role of feedback and congruence. By adopting a cultural-historical lens, which examines the activity pre- and post-implementation of the ICS, we augment understanding of the congruency achieved in the work activity, despite the limitations and changes in work rules and norms in the activity.

\section{Flat Batteries, Ethical Issues, and the Panoptical Gaze}

When focusing on the set of technologies being delivered, several primary contradictions and tensions related to the functionality of the physical artefacts were identified. While each issue could be compensated for by changing working practices or the physical artefact itself, cumulatively they could lead to user resistance and ultimately system failure. The ICS had a high call on the power system of the vehicles and especially so cars. This meant that a vehicle battery could be flattened quite quickly and could delay vehicle movement in response to a call. Standard procedures dictated that vehicle engines should be left idling where there is a risk of this happening, but this is not always practicable and there were a number of instances of other emergency services having to help start ambulances and first responder cars.

A second issue is the utility of the ICS in first response cars. While an ambulance typically carries a two or three person crew, allowing one person to drive and another to operate the ICS (including SatNav systems), the first responder vehicles are usually single crewed. It was not practical for such a user to operate the ICS while moving and, therefore, the user had to either read the message and then drive, or drive and then stop to read the information.

Staff also voiced concern that the ICS screen continued to display patient details in situations where it could be seen by people passing or waiting. This was seen to be legally and ethically unacceptable. The system did default to a screen saver, but only after a pre-set period of time had elapsed. More significantly, on one occasion the system crashed for over 12 hours during an update, after a technician installed what the Trust were assured was a routine patch which would only cause momentary system downtime.

The final primary contradiction was the dual nature of the AVLS as a directional tool and the ability for management to monitor staff movements. This concern was emphasized by crews and managers as it was felt that this provided the means for all of the actions and responses of the crews to be scrutinized in great detail at all times (Brivot and Gendron 2011). Staff in the control function were clear that the system was used to optimize allocation and not to "spy" on crews. As one commented,

I don't need a system to tell me that the crew will stop to get fish and chips if they go near [name] and aren't on a job; I would too. They used to do it and call us to say so, now they can just do it and I can still see where they are if I need a crew. 
Managers were equally clear on this point and as the system was not used oppressively this fear had started to fade.

\section{Redirection of Communication and Disintermediation}

The primary contradictions in terms of technology were compounded by secondary contradictions between the paramedics and the community regarding communication. Communication between control room staff and the ambulance crews could be described as being interstitial in nature (Licoppe and Smoreda 2005). Interstitial communication is represented by a number of factors including proliferation of messages and exchanges between actors and short calls or messages between actors who are close socially. Crews and control room officers noted that the introduction of the ICS reduced radio traffic, making both the control room and the ambulances quieter and more ordered places to work. However, they also recognized that relationships and the social network that existed between staff in the field and in the control room were becoming more fragmented. This loss of social contact (via voice communications) and the general ambient chit-chat that accompanies it made both groups seem more remote to the other and raised concerns that it would affect the social cohesion within the wider group. The concept of "technically mediated sociability" is not a new one; Licoppe and Smoreda (2005, p. 17) explored its impact on social networks and concluded that "relational work, on which strong ties are built is shaped by the tools of communication used in such work." Traditionally with the emergency services, voice communication has been the key method of marking out an interactional space where the users can construct a shared experience and world. It is unclear at this stage how the shifting of much of this communication to unwritten, more rigidly structured and prescriptive data messages will affect the construction of this shared space.

It was also noted that where there could have been friction between certain members of control room staff and members of crews, the use of the ICS eliminated or at least significantly reduced it. The control room staff perceived the reduction in volume and noise in the control room as a positive effect of the technology and they considered that, overall, the introduction of the ICS had probably been a net gain for them. They also noted that some members of crews would "ring in for a chat and just to keep up to date," but recognized that this was likely to fall away and that new members of staff were unlikely to build up the sort of relationships that existed under the previous system. Licoppe and Smoreda (2005, p. 331) note that

At the same time short calls and messages fulfill a phatic function where the discursive content of the communication gesture is less important than the act itself. Phatic communication is spreading, for it constitutes a key resource in the management of quasi-continuously connected relationships.

While we would not agree that in the context of the control room to crew interaction the gesture is less important than the act or the intentional communications that were also occurring, we do feel that it is a key element of those quasicontinuous relationships that exist. Managers within the Trust identified that there were differences in the way information was relayed to and from ambulance crews and that these differences changed the dynamics of interaction with the larger community and, particularly, the control room staff. The quotations below illustrate two specific areas. The first is around the change in the pattern of communication whereby a public information space had been rendered a private one and interaction which was formerly entered into on an opportunistic basis had to be specifically sought. The second illustrates an issue which did, in fact, become of concern to the Trust as a whole.

In the previous system, information from the control room was heard by all crews listening to the AVR system and could provoke a local reaction such as "there is a four vehicle road traffic accident, it is on such and such a road, the chances are we are going to be needed for that, let's start moving." The ICS reduced or eliminated the opportunities for incidental information gathering and exchange within the community. If an incident required more resources, rather than crews being already aware of what may be required, a paramedic noted that "every incident comes to you as a surprise," while another commented that

Yes, you can spend a whole day completely divorced from the control room and never speak to them. That hasn't happened to me yet, but theoretically it is perfectly possible. Which is a shame, because the relationship between road staff and the control room is important otherwise you lose the understanding of each other's positions and their jobs.

Similarly, as another driver noted,

if a driver was lost and crews do switch around the county, other people could chip in: "take a left turn, go down by such and such a pub, don't take such and such a road." Again that now doesn't happen. This is OK when the satellite navigation system is working, but that type of assistance tends to be needed when satellite navigation isn't working; it now has to come directly from control, whereas before drivers would interact between themselves. 
The introduction of a new tool into the activity system had materially changed the community in the short-term as evidenced by the quotation above in that a contradiction for control room staff (a busy and noisy control room environment) was replaced by a problem or potential problem for paramedic crews who used to be able to make use of opportunistically provided information from colleagues but had to change to effectively operate in a more private information space within which such opportunistic communication is virtually impossible. In the longer term, as evidenced by the second quotation, the introduction of the new tool will materially change the level and style of interaction between the paramedic crews as one community and with control room staff as part of a wider community. Thus, the resolution of one set of tensions and contradictions creates new ones which will, in turn, need expansive learning cycles of resolution.

\section{Discussion: Critical Realism and Activity Theory}

Comprehension of technology-mediated organizational change in terms of contradictions in activity systems is a core theme of activity theory and has been discussed in some detail above and elsewhere (Engeström 1987; Helle 2000; Kuutti 1999). We hope that the cases have made clear that identification of activity systems and contradictions within those systems facilitates the analysis of technology-mediated organizational change. Below we will bring out other interesting aspects of the cases, and consider further the relationship between activity theory and critical realism.

In addition to contradictions in activity systems, the cases illustrate the role of congruencies, which foster reproduction rather than change (here there is overlap with Archer's notion of morphostasis). Isolating the key contradictions that emerged from the introduction of a mobile health system and later ICS into paramedic work practices was crucial but it was not sufficient to explain why the systems worked effectively, particularly against the backdrop of the history of high-profile system failure in the Ambulance service (Beynon-Davis 1995, 1999; Fitzgerald and Russo 2005; Hougham 1996; McGrath 2002) and major problems concerning technology and innovation in the public sector generally (Ackroyd et al. 1992; Allen and Karanasios 2011). In case one, we noted that the newly introduced tool was also congruent with elements of the existing work activity system and that there were strong congruencies between internal and external motivation. These congruencies provided a strong stabilizing influence on the activity system. In case two, we described the way in which the tool raised concerns about the potential of control. The issue of control, monitoring, and surveillance is a real concern with the introduction of an information system (Brivot and Gendron 2011). While we noted this as a major concern of the ambulance crews through a process of negotiation between the ambulance crew (the subject) and the control room staff and management (the community), we saw how this fed into a congruency, whereby the ambulance crews accepted that the tool would not be used as a monitoring facility and was seen as beneficial in supporting their norm regarding the need for health and safety. Here we see the paramedics actively influencing the use of the system. While the cumulative effect of the contradictions could lead to systems failure, in this case we see the contradictions being offset by congruencies and a process of feedback and action leading to the transformation of contradictions into congruencies.

A related key theme concerns our findings regarding the inscription of particular social and cultural relations within IS technology, and their effect on organizational power relations. In both cases, tensions and contradictions in the activity system were identified that were related to increased control and surveillance. The introduction of such systems to automate human activity and increase managerial control has been identified as an issue that can lead to the failure of systems. Indeed, in an analysis of a similar system to the one described in this paper, it was seen as leading to active sabotage of the system by ambulance crews (Beynon-Davis 1999; Wastell and Newman 1996). In our second case, the deployment of the ICS created an informational or electronic panopticon (Zuboff 1988) as work which had been invisible to management became visible, thereby increasing managerial control, yet because of the cultural-historical context did not lead to resistance. In the first case, the new capability of the delivery of clot-busting drugs was accompanied by surveillance of the patient. In this case, the ambulance crews actually embraced the panoptic gaze as it was accompanied by the transfer of risk related to clinical decision-making responsibility for the patient from them to the medical staff in the CCU. This led to a reordering of the relationship between the paramedic and the patent. In both cases, while the technologies clearly reinforced conformity and disciplinary control, they are better described as a complex web of power/empowerment (Elmes et al. 2005).

The technology under study in the cases evidently had inscribed within it broadly the same social structural and cultural presuppositions of performance management as did the enterprise system and data warehousing technologies studied through critical realist lenses by Volkoff et al. (2007) and Mutch (2010), as discussed in earlier sections. So in all of these cases, a definite cultural and historical ethos of performance management, closely related, in the case of the UK National Health Service, to the increasing emphasis on 
evidence-based medicine, has been sustained and developed through being inscribed within the features and levels of the newly introduced technology, giving rise to a tendency for a double-edged organizational impact as not only organizational efficiency but also organizational power relations are affected, in ways that must be concretely traced out in each case. It is surely striking that in very different instances, from ambulance dispatch (this paper) to superstore data warehousing (Mutch 2010), broadly similar cultural and social processes related to performance management can be seen to be at work, mediated through IS technology.

A further general theme that we wish to stress is the complex relationship between abstract philosophy and concrete research practice. From the perspective of concrete research, abstract philosophy provides no more than a heuristic guide and, as we have seen in the case of inscription, it is quite possible that the best known heuristic guide offered by critical realists, the morphogenetic approach, can lead to the same results as the guide offered by activity theory. Indeed, it is not just with regard to inscription but also the very notion of contradiction and change of the system as a whole that critical realism-inspired work in IS has sometimes arrived at the same position as activity theory. A striking example is Volkoff et al.'s critical realism-inspired finding that the introduction of a new enterprise system into an organization will bring "tensions" due to contradictory organizational outcomes that can lead to organizational change (pp. 746-747). As we have seen, it is a central premise of activity theory that tensions and contradictions lead to organizational change.

Given that the same key concrete research results have been achieved by two different respective abstract guides for research, activity theory on the one hand and the morphogenetic approach on the other, it cannot be argued that just one of these approaches is the sole valid basis upon which to theorize organizational (and, generally, socio-cultural) change. We, therefore, hope to have shown why we disagree with Archer's claim that analytical dualism provides the only valid way to theorize change (Archer and Elder-Vass 2012). The broader issue of how to relate the abstract and the concrete has notably been argued to reveal a weakness of both critical realism and activity theory within the wider literature. For example, drawing on Ilyenkov's (1982) seminal work on ascending from the abstract to the concrete, Brown et al. (2002) have argued that the critical realist attempt to deal with the relation between the abstract and the concrete in terms of the stratification of mechanisms does not help to discern the abstract or systemic significance of concrete (local and specific) cases. Jones (2009) has similarly argued that activity theory does not help to place concrete or local activity systems within an abstract or global context, suggesting that this is one area where activity theory literature has tended to misunderstand Ilyenkov. Clearly contentious, further discussion of the complex relationship between the abstract and the concrete is beyond the scope of this paper.

Finally, we hope the foregoing has made clear that our presentation of activity theory is not an attempt to reinforce or present a theoretical monopolistic or oligopolistic intellectual position. Indeed, we would argue that our use of activity theory demonstrates the openness of our approach to the application of other theory. For example, in our analysis of the second case, our identification of secondary contradictions between the paramedics (subject) and the command and control (community) was enabled by our use of activity theory; however, in interpreting and explaining this contradiction we turned to theories developed within the field of communication. In common with Nardi and O'Day (1999), we believe that a key benefit of an activity theory framework is that it allows diverse approaches to be accommodated within a larger theoretical framework. We propose a pragmatic rather than a doctrinaire approach and suggest that it is broad enough to accommodate many base disciplines and flexible enough to do so within an overall framework that provides a common set of concepts and vocabulary.

\section{Conclusion}

This paper has argued that activity theory addresses difficult issues regarding culture and technology in a materialist way that is broadly consonant with critical realism, albeit critical realism itself has only recently begun to address these themes (in large part spurred on by critical realist IS scholars). Activity theory does so through an abiding focus on activity systems as contradictory unities of subjective and objective aspects in ongoing development. The notion of the activity system as the unit of analysis has been argued to differ from Archer's analytical dualism, where system and activity are analytically held apart, but employment of both approaches has been argued to be potentially fruitful. The potential benefits of extending and developing critical realism through activity theory are broad and deep and have only been briefly touched upon in this paper. At the same time, the paper has illustrated that activity theory itself benefits from the key strengths of critical realism, namely the critical realist materialist ontology of emergent natural and social powers.

The focus of the paper has been on understanding technologymediated organizational change in the particular cases of paramedic treatment of heart attacks and of ambulance dispatch, employing the activity theoretic notions of contradiction, tension, and development. In order to help achieve such understanding, the paper has developed the nascent 
critical realism-inspired notion that social structure and culture are inscribed within IS technology. The paper has found that broadly similar cultural and structural presuppositions of performance management have been inscribed within the IS technology of the public sector cases under study as have been inscribed within private sector superstore data warehousing and enterprise systems studied in research by critical realist IS scholars. Moreover, the paper has found that such inscribed relations of performance management have had a distinctive double-edged impact across all of these different forms of organization, in entailing changes in organizational power relations as well as efficiency outcomes. This finding of a similar double-edged pattern to IS-mediated organizational change across very different forms of organization has been achieved through both critical realism-inspired and activity theoretic approaches, illustrating the analytical power of these two approaches in identifying wider socio-cultural forces at work in organizational change and development, a power that we argue is enhanced by recognizing the broadly complementary relationship of critical realism and activity theory.

We have argued that activity theory has, in many implementations up until now, concentrated on identifying contradictions and tensions within activity systems and used them as the basis for expansive learning cycles which can, as posited in the third-generation evolution of activity theory (Daniels 2001), lead to a culturally more advanced activity system being generated through the action of a number of changing systems on aspects of the central activity system studied. While there are clear links and explanatory paths that show the power of contradictions and tensions to provoke action which in turn develops activity systems in new and expanded ways there are also issues of existing congruencies and potential future ones. This notion of congruency is similar to Archer's (1995) use of the notion of morphostasis and can be taken as one more example of how the two approaches are mutually complementary. The notion of morphostasis has its roots in systems theory and we have also brought out parallels between systems theory (the notion of feedback) and activity theory (the notion of contradiction and of congruency) in relation to critical realism helping to fill a gap in the critical realist literature in this regard (Mingers 2011). In short, we have tried to demonstrate that critical realism and activity theory are essential to IS studies and hope to have stimulated further work developing this exciting new area of research.

\section{References}

Ackroyd, S., Harper, R., Hughes, J.A., Shapiro, D., and Soothill, K. 1992. New Technology and Practical Police Work: The Social Context of Technical Innovation, Buckingham, UK: Open University Press.
Allen, D., and Karanasios, S. 2011. "Critical Factors and Patterns in the Innovation Process," Policing: A Journal of Policy and Practice (5: 1), pp. 87-97.

Allen, D., Karanasios, S., and Slavova, M. 2011. "Working with Activity Theory: Context, Technology, and Information Behavior," Journal of the American Society for Information Science and Technology (62:4), pp. 776-788.

Allen, D. K., and Wilson, T. D. 2004. “Action, Interaction and the Role of Ambiguity in the Introduction of Mobile Information Systems in a UK Police Force," in Proceedings of the IFIP TC8 Working Conference on Mobile Information Systems, E. Lawrence, B. Pernici, and J. Krogstie (eds.), New York: Springer, pp. 15-37.

Archer, M. 1995. Realist Social Theory: The Morphogenetic Approach, Cambridge, UK: Cambridge University Press.

Archer, M. 1996. Culture and Agency ( $2^{\text {nd }}$ ed., rev.), Cambridge, UK: Cambridge University Press.

Archer, M., and Elder-Vass, D. 2012. "Cultural System or Norm Circles? An Exchange," European Journal of Social Theory (15:1), pp. 93-115.

Bakhurst, D. 1991. Consciousness and Revolution in Soviet Philosophy: From the Bolsheviks to Ilyenkov, Cambridge, UK: Cambridge University Press.

Beynon-Davis, P. 1995. “Information System 'Failure' and Risk Assessment: The Case of the London Ambulance Service Computer Aided Despatch System," in Proceedings of the Third European Conference on Information Systems, G. I. Doukidis, B. Galliers, T. Jelassi, H. Krecmar, and F. Land (eds.), Athens, Greece, pp. 1153-1170.

Beynon-Davis, P. 1999. "Human Error and Information Systems Failure: The Case of the London Ambulance Service ComputerAided Despatch System Project," Interacting with Computers (11), pp. 699-720.

Bhaskar, R. 1975. Realist theory of Science, London: Harvester Wheatsheaf.

Bhaskar, R. 1979. The Possibility of Naturalism, Hemel Hempstead, UK: Harvester.

Blunden, A. 2010. An Interdisciplinary Theory of Activity, Leiden, The Netherlands: Brill.

Brivot, M., and Gendron, Y. 2011. "Beyond Panopticism: On the Ramifications of Surveillance in a Contemporary Professional Setting," Accounting, Organizations and Society (36: 3), pp. 135-155.

Brooks, L., Atkinson, C., and Wainwright, D. 2008. "Adapting Structuration Theory to Understand the Role of Reflexivity: Problematization, Clinical Audit and Information Systems," International Journal of Information Management (28:6), pp. 453-460.

Brown, A. 2002. "Developing Realistic Philosophy: From Critical Realism to Materialist Dialectics," in Critical Realism and Marxism, A. Brown, S. Fleetwood, and J. M. Roberts (eds.). London: Routledge. pp.168-86

Brown, A., Slater, G., and Spencer, D. A. 2002. "Driven to Abstraction? Critical Realism and the Search for the 'Inner Connection' of Social Phenomena," Cambridge Journal of Economics (26:6), pp. 773-788. 
Buckley, W. F. 1967. Sociology and Modern Systems Theory, Upper Saddle River, NJ: Prentice Hall.

Capper, P., and Williams, B. 2004. "Enhancing Evaluation Using Systems Concepts," American Evaluation Association, November (http://users.actrix.co.nz/bobwill/activity.doc; accessed February 27, 2012).

Carlsson, S. A. 2012. "The Potential of Critical Realism in IS Research," in Information Systems Theory, Y. K. Dwivedi, M. R. Wade, and S. L. Schneberger (eds.). New York: Springer, pp. 281-304.

Cole, M., and Engeström, Y. 1993. “A Cultural-Historical Approach to Distributed Cognition," in Distributed Cognitions, Psychological and Educational Considerations, G. Salomon (ed.), Cambridge, UK: Cambridge University Press, pp. 1-46.

Comfort, L. K. 1994. "Self-Organization in Complex Systems," Journal of Public Administration Research and Theory (4:3), pp. 393-410.

Daniels, H. 2001. Vygotsky and Pedagogy, London: Routledge Falmer.

Davis, F. D. 1989. "Perceived Usefulness, Perceived Ease of Use, and User Acceptance of Information Technology," MIS Quarterly (13:3), pp. 319-340.

DeLone, W. H., and McLean, E. R. 2003. "The DeLone and McLean Model of Information Systems Success: A Ten-Year Update," Journal of Management Information Systems (19:4), pp. 9-30.

Dobson, P., Myles, J., and Jackson, P. 2007. "Making the Case for Critical Realism: Examining the Implementation of Automated Performance Management Systems," Information Resources Management Journal (20:2), pp. 138-152.

Doolin, B. 2003. "Narratives of Change: Discourse, Technology and Organization," Organization (10:4), pp. 751-770.

Eisenhardt, K. M. 1995. "Building Theories from Case Study Research," in Longitudinal Field Research Methods: Study Processes of Organizational Change, G. P. Huber and A. H. Van de Ven (eds.), London: Sage Publications, pp. 65-90.

Elder-Vass, D. 2010. The Causal Power of Social Structures: Emergence, Structure and Agency, Cambridge, UK: Cambridge University Press.

Elmes, M. B., Strong, D. M., and Volkoff, O. 2005. "Panoptic Empowerment and Reflective Conformity in Enterprise SystemsEnabled Organizations," Information and Organization (15:1), pp. 1-37.

Engeström, Y. 1987. Learning by Expanding: An ActivityTheoretical Approach to Developmental Research, Helsinki: Orienta-Konsultit.

Engeström, Y. 1993. "Developmental Studies of Work as a Testbench of Activity Theory: The Case of Primary Care Medical Practice," in Understanding Practice: Perspectives on Activity and Context, S. Chaiklin and J. Lave (eds.), Cambridge, UK: Cambridge University Press, pp. 64-103.

Engeström, Y. 2000. "Activity Theory as a Framework for Analyzing and Redesigning Work," Ergonomics (43:7), pp. 960-974.

Engeström, Y. 2001. "Expansive Learning at Work: Toward an Activity Theoretical Reonceptualization," Journal of Education and Work (14:1), pp. 133-156.
Fairclough, N., Jessop, B., and Sayer, A. 2004. "Critical Realism and Semiosis," in Realism, Discourse and Deconstruction, J. Joseph and J. M. Roberts (eds.), London: Routledge, pp. 23-42.

Faulkner, P., and Runde, J. 2009. "On the Identity of Technological Objects and User Innovations in Function," Academy of Management Review (34:3), pp. 442-462.

Faulkner, P., and Runde, J. 2011. "The Social, the Material, and the Ontology of Non-Material Technological Objects," in Proceedings of the $27^{\text {th }}$ EGOS Colloquium, July 6-9, Gothenburg, Sweden, pp. 1-33.

Fitzgerald, G., and Russo, N. L. 2005. "The Turnaround of the London Ambulance Service Computer-Aided Despatch System (LASCAD)," European Journal of Information Systems (14), pp. 244-257.

Fleetwood, S. 2005. "Ontology in Organization and Management Studies: A Critical Realist Perspective,” Organization (12:2), pp. 197-222.

Foot, K. A. 2001. "Cultural-Historical Activity Theory as Practice Theory: Illuminating the Development of Conflict-Monitoring Network," Communication Theory (11), pp. 56-83.

Fuentes, R., Gómez, J., Pavón, J., and Uden, L. 2004. “Activity Theory Applied to Requirements Elicitation of Multi-Agent Systems," in Proceedings of the First International Workshop on Activity Theory Based Practical Methods for IT-Design, O. W. Bertelsen, M. Korpela, and A. Mursu (eds.), September 2-3, Copenhagen, pp. 22-31.

Guy, E. S. 2005. ““....real, concrete facts about what works ...': Integrating Evaluation and Design Through Patterns," in Proceedings of the 2005 International ACM SIGGROUP Conference on Supporting Group Work, N. Pendergast, K. Schmidt, G. Mark, and M. Ackerman (eds.), New York: ACM Press, pp. 99-108.

Harvey, L. J., and Myers, M. D. 2002. "Scholarship and Practice: The Contribution of Ethnographic Research Methods to Bridging the Gap," in Qualitative Research in Information Systems: A Reader, M. D. Myers and D. E. Avison (eds.), London: Sage Publications, pp. 169-180.

Helle, M. 2000. "Disturbances and Contradictions as Tools for Understanding Work in the Newsroom," Scandinavian Journal of Information Systems (12:1), pp. 81-113.

Hougham, M. 1996. "London Ambulance Computer Aided Dispatch System," International Journal of Project Management (14: 2), pp. 103-110.

Ilyenkov, E. V. 1977. Dialectical Logic: Essays on its Theory and History, Moscow: Progress.

Ilyenkov, E. V. 1982. The Dialectics of the Abstract and the Concrete in Marx's "Capital”, Moscow: Progress.

Jones, P. E. 2009. "Breaking Away from Capital? Theorising Activity in the Shadow of Marx," Outlines (11:1), pp. 45-58.

Jones, R. A., Jimmieson, N. L., and Griffiths, A. 2005. "The Impact of Organizational Culture and Reshaping Capabilities on Change Implementation Success: The Mediating Role of Readiness for Change," Journal of Management Studies (42:2), pp. 361-386.

Kaptelinin, V., Nardi, B. A., and Macaulay, C. 1999. “The Activity Checklist: A Tool for Representing the 'Space' of Context," Interactions (6:4), pp. 27-39. 
Karanasios, S., Allen, D., and Vardaxoglou, G. 2009. "Innovation in UK Law Enforcement: The Emergence of Mobile Data," in Proceedings of the $15^{\text {th }}$ Americas Conference on Information Systems, August 6-9, San Francisco.

Khoo, H. M., and Robey, D. 2007. "Deciding to Upgrade Packaged Software: A Comparative Case Study of Motives, Contingencies and Dependencies," European Journal of Information Systems (16:5), pp. 555-567.

Kim, H.-W., and Kankanhalli, A. 2009. "Investigating User Resistance to Information Systems Implementation: A Status Quo Bias Perspective," MIS Quarterly (33: 3), pp. 567-582.

Kuutti, K. 1999. "Activity Theory, Transformation of Work, and Information Systems Design," in Perspectives on Activity Theory -Learning in Doing: Social, Cognitive and Computational Perspectives, Y. Engeström, R. Miettinen, and R.-L. Punamäki-Gitai (eds.), Cambridge, UK: Cambridge University Press, pp. 360-376.

Leont'ev, A. N. 1978. Activity, Consciousness, and Personality, Englewood Cliffs, NJ: Prentice-Hall.

Levins, R. 1998. "Dialectics and Systems Theory," Science and Society (62:3), pp. 375-399.

Licoppe, C., and Smoreda, Z. 2005. “Are Social Networks Technologically Embedded? How Networks Are Changing Today with Changes in Communication Technology," Social Networks (27:4), pp. 317-335.

Lyytinen, K., and Newman, M. 2008. "Explaining Information Systems Change: A Punctuated Socio-Technical Change Model," European Journal of Information Systems (17), pp. 589-613.

Manning, P. K. 1996. "Information Technology in the Police Context: The 'Sailor' Phone," Information Systems Research (7:1), pp. 52-62.

McGrath, K. 2002. "The Golden Circle: A Way of Arguing and Acting About Technology in the London Ambulance Service," European Journal of Information Systems, (11), pp. 251-266.

Mingers, J. 2001. "Combining IS Research Methods: Towards a Pluralist Methodology," Information Systems Research (12:3), pp. 240-259.

Mingers, J. 2006. Realizing Systems Thinking: Knowledge and Action in Management Science, New York: Springer.

Mingers, J. 2011. "The Contribution of Systemic Thought to Critical Realism," Journal of Critical Realism (10: 3), pp. 303-330.

Murphy, E., and Rodriguez-Manzanares, M. A. 2008a. "Contradictions Between the Virtual and Physical High School Classroom: A Third-Generation Activity Theory Perspective," British Journal of Educational Technology (39:6), pp. 1061-1072.

Murphy, E., and Rodriguez-Manzanares, M. A. 2008b. "Using Activity Theory and its Principle of Contradictions to Guide Research in Educational Technology," Australasian journal of Educational Technology (24:4), pp. 442-457.

Mutch, A. 2010. "Technology, Organization and Structure: A Morphogenetic Approach," Organization Science (21:2), pp. 507-520.

Nardi, B., and O'Day, V. 1999. Information Ecologies, Using Technology with Heart, Cambridge, MA: MIT Press.
Nelhaus, T. 2007. "Culture, Cultural Analysis," in Dictionary of Critical Realism, M. Hartwig (ed.), London: Routledge, pp. 109-111.

Nelson, C. 2002. "Contradictions in Learning to Write in a Second Language Classroom: Insights from Radical Constructivism, Activity Theory, and Complexity Theory," unpublished doctoral dissertation, The University of Texas at Austin, Austin, TX.

O'Leary, D. E. 2010. "Enterprise Ontologies: Review and an Activity Theory Approach," International Journal of Accounting Information Systems (11:4), pp. 336-352.

Orlikowski, W. J. 2010. "The Sociomateriality of Organizational Life: Considering Technology in Management Research," Cambridge Journal of Economics (34:1), pp. 125-141.

Oroviogoicoechea, C., and Watson, R. 2009. "A Quantitative Analysis of the Impact of a Computerized Information System on Nurses' Clinical Practice Using a Realistic Evaluation Framework," International Journal of Medical Informatics (78:12), pp. 839-849.

Petter, S., DeLone, W., and McLean, E. 2008. "Measuring Information Systems Success: Models, Dimensions, Measures, and Interrelationships," European Journal of Information Systems (17:3), pp. 236-263.

Pica, D., Sørensen, C., and Allen , D. K. 2004. "On Mobility and Context of Work: Exploring Mobile Police Work," in Proceedings of the $37^{\text {th }}$ Hawaii International Conference on System Sciences, January 5-8, Los Alamitos, CA: IEEE Computer Society Press.

Quek, A., and Shah, H. 2004. "The Activity Theoretical Iterative Evaluation Method," in Proceedings of the $1^{\text {st }}$ International Workshop on Activity Theory Based Practical Methods for IT Design, O. W. Bertelsen, M. Korpela, and A. Mursu (eds.), Copenhagen, Denmark.

Rowley, J., and Urquhart, C. 2007. "Understanding Student Information Behavior in Relation to Electronic Information Services: Lessons from Longitudinal Monitoring and Evaluation, Part 1," Journal of the American Society for Information Science and Technology (58:8), pp. 1162-1174.

Sawyer, S., and Southwick, R. 2002. "Temporal Issues in Information and Communication Technology Enabled Organizational Change: Evidence from an Enterprise Systems Implementation," The Information Society (18), pp. 263-280.

Sayer, A. 1992. Method in Social Science: A Realist Approach, London: Routledge.

Shannon, C., and Weaver, W. 1949. The Mathematical Theory of Communication, Champaign, IL: University of Illinois Press.

Sintchenko, V., and Coiera, E. W. 2003. "Which Clinical Decisions Benefit from Automation? A Task Complexity Approach," International Journal of Medical Informatics (70), pp. 309-316.

Sørensen, C., and Pica, D. 2005. "Tales from the Police: Rhythms of Interaction with Mobile Technologies," Information and Organization (15:2), pp. 125-149.

Spasser, M. A. 1999. "Informing Information Science: The Case for Activity Theory," Journal of the American Society for Information Science and Technology (50:12), pp. 1136-1138. 
Strong, D. M., and Volkoff, O. 2010. "Understanding Organization-Enterprise Fit: A Path to Theorizing the Information Technology Artifact," MIS Quarterly (34:4), pp. 731-756.

Venkatesh, V., Morris, M., Davis, G., and Davis, F. 2003. "User Acceptance of Information Technology: Toward a Unified View," MIS Quarterly (27:3), pp. 425-478.

Volkoff, O., Strong, D. M., and Elmes, M. B. 2007. “Technological Embeddedness and Organizational Change," Organization Science (18:5), pp. 832-848.

Von Bertalanffy, L. 1971. General Systems Theory, London: Penguin.

Vygotsky, L. 1978. Mind in Society: The Development of Higher Psychological Processes, Cambridge, MA: Harvard University Press.

Wastell, D., and Newman, M. 1996. "Information Systems Design, Stress and Organisational Change in the Ambulance Services: A Tale of Two Cities.," Accounting, Management \& Information Technology (6:4), pp. 283-299.

Wheelahan, L. 2007. "Blending Activity Theory and Critical Realism to Theorise the Relationship Between the Individual and Society and the Implications for Pedagogy," Studies in the Education of Adults (39:2), pp. 183-196.

Wiener, N. 1948. Cybernetics: Or Communication and Control in the Animal and the Machine, Cambridge, MA: MIT Press.

Wilson, T. D. 2008. "Activity Theory and Information Seeking," Annual Review of Information Science and Technology (42), pp. 119-161.

Wiredu, G. O. 2007. "User Appropriation of Mobile Technologies: Motives, Conditions and Design Properties," Information and Organization (17:2), pp. 110-129.

Wiredu, G. O., and Sørensen, C. 2006. "The Dynamics of Control and Mobile Computing in Distributed Activities," European Journal of Information Systems (15), pp. 307-319.

Zuboff, S. 1988. In the Age of the Smart Machine, New York: Basic Books

\section{About the Authors}

David K. Allen is a senior lecturer in Information Management in the Leeds University Business School and director of the AIMTech Research Group (www.aimtech.org). Over the past 10 years, he has spent most of his time exploring information management practices and the influence of technology on organizational work practices in a range of interesting environments. This has been facilitated by over 45 externally funded projects conducted with colleagues in the AIMTech Research Group. During this period, David has explored the use of activity theory to theorize change and influence practice. His work has been published in Journal of the American Society for Information Systems and Technology, Information Systems Journal, and elsewhere. His recent projects have focused on information practices in high velocity environments and understanding the information sharing practices and innovation process related to the development of novel new technologies. He led the University of Leeds involvement in the EU project WiMagic and is currently working in the Network of Excellence ACROPOLIS and the seventh framework project, IMReal.

Andrew Brown is a senior lecturer in Economics at the Centre for Employment Relations Innovation and Change, Leeds University Business School, the University of Leeds. His substantive and theoretical research interests include financialization, the euro crisis, job quality, job satisfaction, value theory, and political economy, His philosophical and methodological interests include critical realism, dialectics, activity theory, and the philosophy of E. V. Ilyenkov. He has published in these areas in journals such as Work, Employment and Society, Cambridge Journal of Economics, Human Resource Management Journal, Journal of Economic Methodology, Eastern Economic Journal, International Review of Applied Economics, and Journal of Post Keynesian Economics, and in the books Critical Realism and Marxism (coedited with Steve Fleetwood and John M. Roberts) and The Euro: Evolution and Prospects (coauthored with Philip Arestis and Malcolm Sawyer). He currently jointly coordinates the major EU FP7 Financialisation, Economy, Society and Sustainable Development (FESSUD) project.

Stan Karanasios completed his Ph.D. at Victoria University in Melbourne, Australia, in the area of small business and information communication technology adoption in developing countries. During his doctoral studies, Stan worked for Monash University and RMIT University in Australia. Before academia, he spent some time working for Goldman Sachs JBWere and Hitachi Data Systems. After completing his doctorate, he joined the AIMTech Research Group at the University of Leeds. His research interests span ICT in society, with specific interests in emergency response, ICT development, and the use and extension of activity theory in IS research. He has published in several prominent information systems journals. Currently he is working on the ImREAL project, developing methods to make sense of data in social media, and the ACROPOLIS project, an ICT Network of Excellence on Telecommunications project.

Alistair Norman completed his Ph.D. at the University of Leeds after completing Master's degrees (in Management Sciences and in Information Systems) at the University of Manchester and the University of Salford. Alistair's doctoral work formalized and developed his existing academic and commercial interest in the concept of mobility and the effects it has on the way that those equipped with mobile technologies undertake and manage their work. During his career, Alistair has worked extensively in business education and technology education for organizations in the UK, Europe, and the Middle East, and assisted non-UK organizations in the development of management and project management capacity for the integration of UK qualifications into their existing processes. More recently, Alistair's work has been focused on the UK public safety community and he has worked with emergency services in the UK examining their deployment, use, and management of mobile data systems. He is working on the ImREAL project to support the development of the next generation of simulated learning environments. 